\title{
Understanding age-triggered cognitive assessments of late-career physicians
}

\author{
Edward P. Monico*1, Valerie R.C. Allusson², Arthur Calise ${ }^{2}$, Ronald N. Riner ${ }^{2}$ \\ ${ }^{1}$ Department of Emergency Medicine, Yale University School of Medicine, New Haven, United States \\ ${ }^{2}$ Hackensack Meridian Health Mountainside Medical Center Institute, Montclair, United States
}

Received: July 21, 2019

DOI: $10.5430 /$ jha.v8n5p26
Accepted: August 6, 2019

Online Published: August 28, 2019

\begin{abstract}
Late-career physicians now represent a significant part of the physician workforce in the United States. The American Medical Association Council on Medical Education tracks physician demographic data and found that in 1975 there were 50,993 practicing physicians 65 years or older, but by 2013, this number had risen to 241,641 physicians, a 374\% increase. The AMA Council also concluded that aging was associated with decreased processing speed, increased difficulty inhibiting irrelevant information, reduced hearing and visual acuity, decreased manual dexterity and visuospatial ability. There is mounting concern that the effects of aging can adversely impact the practice of medicine by late-career physicians. Although results are mixed, studies suggest late-career physicians have a higher rate of disciplinary action, fail to acquire new knowledge and have greater variability in test scores and their patients experience higher mortality rates after complex surgical procedures. Hospital administrators in their efforts to assess cognition of their aging medical staff are limited by the absence of validated metrics when it comes to older individuals with above-average years of education. Also, attempts to curtail medical practice based on age are fraught with legal implications arising from the Americans with Disabilities Act of 1990 and the Age Discrimination in Employment Act of 1967. We examined the issues hospital administrators face when formulating policies regulating the medical practice of late-career physicians. Our review summarizes the state of the literature of late-career physicians, reviews the legal implications of policies regarding age and the practice of medicine and offers our experience in creating a late-career physician policy for a multi-disciplinary medical staff.
\end{abstract}

Key Words: Late-career physicians, Cognitive testing, Age Discrimination in Employment Act, Americans with Disabilities Act

\section{INTRODUCTION}

The practice of medicine requires its practitioners to assimilate large sums of technical data and incorporate medical innovation that can challenge care standards or even contradict previous practice doctrine. In its application to human frailty, medical science is a tool honed only by the competent physician. The growth of the medical profession as a public institution and the commercialization of medical practice have shaped the contours and behavior of society in demanding greater obligations and accountability on the part of the medical profession to monitor its practitioners. Against this backdrop and due to the high variability of the effect of age on physicians and the increase representation of late-career physicians in the US medical work force, the medical community finds itself between the Charybdis of individual autonomy and the Scylla of patient safety.

${ }^{*}$ Correspondence: Edward P. Monico; Email: edward.monico@yale.edu; Address: Department of Emergency Medicine, Yale University School of Medicine, New Haven, United States. 


\section{LATE-CAREER PHYSICIANS}

Late-career physicians now represent a significant part of the physician workforce in the United States. The American Medical Association Council on Medical Education tracks physician demographic data and found that in 1975 there were 50,993 practicing physicians 65 years or older, but by 2013 , this number had risen to 241,641 physicians, a $374 \%$ increase. ${ }^{[1]}$ By all accounts subsequent assessments on aging physicians show these trends are continuing. Best estimates put practicing physicians older than 65 at $23 \%$ in 2015. ${ }^{[2]}$ Meanwhile, some specialties are disproportionately represented by the older physician. For instance, a study conducted by the Association of American Medical Colleges found that in $201585 \%$ of practicing pulmonologists were 55 years or older. ${ }^{[3]}$ The fact that multiple national organizations monitor this data is more than coincidence. It speaks to the growing interest in the practice of medicine by older physicians.

Although a lack of consensus exists on what to do about aging physicians, there appears to be a general agreement that the effects of aging can adversely impact the practice of medicine. The AMA Council on Medical Education reviewed the literature on how aging affects physicians' cognitive and sensory abilities. ${ }^{[2]}$ They concluded that aging was associated with decreased processing speed, limiting ability to complete tasks, increased difficulty inhibiting irrelevant information, reduced hearing and visual acuity and decreased manual dexterity and visuospatial ability. ${ }^{[4-8]}$ It is difficult to imagine a medical practice representing a safe harbor from the effects of aging on its practitioners.

However, the effects of age on cognition are not linear, which complicates the issue of age and medical practice. When researchers compared the cognitive function of physicians to non-physician participants, they found as age increases, cognition decreases but with increasing variation. ${ }^{[9]}$ For instance, older age groups contained physicians with fully intact cognitive scores while younger age groups contained some physicians with dramatic cognitive decline. ${ }^{[9]}$ Findings like these underlie the difficulty in applying age-based recommendations to the issue of how to assess cognitive decline in late-career physicians. Further complicating the matter is the fact that age alone does not cause cognitive impairment, ${ }^{[10]}$ and standard cognitive tests have limited predictive value in assessing intelligent individuals when compared to age-matched controls. ${ }^{[11]}$

Other research suggests physicians have increasing difficulty practicing medicine as they age without offering any causal explanations. For instance, of the $10 \%$ of non-specialist physicians in office practices evaluated in the Peer Assess-

Published by Sciedu Press ment program in Ontario, Canada that needed significant assistance with their practice, $18 \%$ of these were over the age of 70-a significant overrepresentation of this age cohort. ${ }^{[12]}$ The risk of disciplinary action also rises the longer a physician practices. Morrison and Wickersham state, in their study of physicians being disciplined for negligence or incompetence, that physicians in practice for more than 20 years are more likely to be disciplined, but they offer no explanation as to why. ${ }^{[13]}$ In some complex procedures, the patients of surgeons older than 60 have higher mortality rates than those of younger surgeons. ${ }^{[14]}$ Similarly, knowledge-based test scores decline while test score variation increases with age indicating age may not be the only factor driving test scores in physicians over age sixty-five. Moreover, interpreting the meaning of test scores in late-career physicians is no less complex. Research suggests that lower scores by older physicians more accurately reflects a failure to acquire new knowledge rather than the loss of prior knowledge. ${ }^{[15]}$

\section{STATUS OF OVERSight}

Standards of professional behavior impose an affirmative duty on physicians to report to relevant authorities significantly impaired or incompetent colleagues. ${ }^{[16]}$ In November 2015, the AMA Council on Medical Education codified this standard when it issued a report on "Competency and the Aging Physician" that called for "guidelines/standards for monitoring and assessing both their own and their colleagues' competency."[17]

However, despite an affirmative duty to report, physicians are leery of reporting other physicians. Reasons for this may be guilt of betraying a mentor or fear of retribution from higher ranking physicians. Moreover, the hesitation to report a colleague may be reinforced by an institution's continuous quality improvement strategy when those endeavors view individual reporting as punitive and counter-productive. ${ }^{[16]}$ The failure of peer monitoring is not isolated to the latecareer physician but spans the breadth of clinical practice in what has been coined a "cultural aversion" to reporting. ${ }^{[18]}$ More pragmatic reasons for the failure of peer monitoring exists such as jeopardizing hospital revenue from a physician of questionable competence in localities fraught with difficulty in securing physician coverage. ${ }^{[19]}$ A national survey found that $45 \%$ of practicing physicians with direct personal knowledge of a physician in their hospital group or practice who was impaired or incompetent did not report that physician. ${ }^{[20]}$ Another study found that even when referrals to an assessment program were made, only $20 \%$ of the referrals were from within the hospital or from the impaired physician's practice partners. ${ }^{[21]}$ Whether driven by economics or collegial loyalty, peer surveillance alone has proved an unre- 
liable means of bringing impaired physicians to the attention of hospital administrators.

\section{LIMITS OF COGNITIVE TESTING}

Despite the large body of evidence implicating cognitive impairment in older adults, it is also recognized that aging, per se, does not necessarily result in cognitive impairment. ${ }^{[22]}$ While this conundrum contributes to the dilemma of exactly whom to test, it simultaneously justifies the need for such testing. Similarly, within the wide variation of cognitive limitations that accompany aging, it remains unclear which specific limitations are detrimental to a physician's occupational performance again hindering surveillance efforts since cognitive tests vary in focus. ${ }^{[23]}$

Also, innate mechanisms employed by aging physicians to prolong their practice may represent a two-edge sword for the physician. Aging physicians tend to relinquish analytic for non-analytic processes like pattern recognition. ${ }^{[4]}$ However, evolving and complex clinical scenarios may challenge nonanalytic processes and can lead to diagnostic errors which may, in part, explain some negative quality metrics associated with late-career physicians. ${ }^{[23]}$ Some aspects of aging may be more amenable to testing than cognition but, in the end, they tend to cloud more than clarify the issue. For in stance, manual dexterity and visuospatial ability are easier to quantitate. Moreover, both tend to decrease with age and do so independent of cognition. ${ }^{[24]}$ However, relative preservation in these areas in physicians with cognitive impairment may be falsely reassuring in some testing schemes.

Although an obvious causal relationship between age and cognition may be lacking, quality of care metrics in latecareer physicians raises concern that age in some way negatively impacts quality medical care. While which aspects of impaired cognition are responsible for eroding the provision of medical care have been difficult to detect, the aspects of care affected have been easier to identify. Incorporating updated treatment approaches including evolving medication regimens occurs less often among older primary care physicians. ${ }^{[14,25]}$ A systematic review of existing literature found as career length increases, knowledge, adherences to evidence-based standard of care and favorable patient outcomes decreases. ${ }^{[26]}$ Similarly, increasing years in practice have been associated with longer hospital stays and higher mortality rates. ${ }^{[27]}$ The association between years of practice and compromised medical care is not attributed solely to physicians practicing in the United States. A peer assessment program in Ontario found physician age to be an independent predictor of substandard care and medical documentation. ${ }^{[28]}$ Similarly, in the United Kingdom, a disproportionate number of physician practices classified as poorly performing in terms of quality and outcomes were staffed by elderly general practitioners. ${ }^{[29]}$

Findings from regulatory and medical oversight authorities resonate with the academic literature on late-career physician impairments. State medical board statistics demonstrate that advancing age is a risk factor for actions against physician licensure. ${ }^{[13,30]}$ In Canada, review by the Quebec licensing authority found that physicians over seventy years of age were three times more likely to experience license revocation than those under seventy and were half as likely to successfully remediate. ${ }^{[31]}$ A review of Medicare data found that the combination of advanced age and low procedural volume in surgeons correlates with poor outcomes in certain abdominal and chest procedures. ${ }^{[16]}$ Also, physicians age sixty-five and older lagged behind in maintaining their continuing educational activities compared to their younger colleagues. ${ }^{[32]}$ Due to insufficient data, how late-career proceduralists compare with their non-proceduralist colleagues is difficult to say.

The fact that other studies have shown that physicians over the age of sixty engage in medical pursuits on par with their younger colleagues exemplifies the complexity of age on medical practice. ${ }^{[4,33]}$ For instance, a study sponsored by the American College of Surgery found that half of practicing surgeons over sixty-five reported no reduction in their case complexity, and the majority kept pace with continuing education requirements and maintained academic pursuits. ${ }^{[34]}$ Similarly, other studies demonstrated no age-related differences in outcomes between older and younger physicians. For instance, with certain surgical procedures including lung resection and abdominal aortic aneurysm repair, one researcher observed that the most experienced surgeons achieved the lowest mortality rates. ${ }^{[8]}$ Another study found no significant difference in thirty-day mortality rates between younger and late-career physician cohorts when each admitted a high volume of elderly inpatients. ${ }^{[35]}$ In fact, the over-sixty-five physician population enjoys the lowest medical malpractice incidence and claims rate ${ }^{[36]}$ as well as the fewest unsolicited patient complaints, ${ }^{[37]}$ a marker for medical malpractice risk. Some late-career physicians who evolve away from clinical medicine show favorable statistics in areas where cognitively impaired individuals typically show vulnerability. Beyond Blue, an Australian study analyzing physicians of all ages found that those above sixty had the lowest rates of suicidal ideation, anxiety, depression, burnout, and cynicism. ${ }^{[38]}$

\section{LEGAL IMPLICATIONS}

There is currently no law regulating competency assessments of the aging physician. However, hospital administrators and 
the medical community at large must consider a host of legal implications when formulating policy specific to aging physicians and their ability to work. ${ }^{[39]}$ Through the Civil Rights Act of 1964, the Supreme Court made clear its intention to prohibit discrimination based on "race, color, religion, sex or national origin". With the enactment of the Federal Age Discrimination in Employment Act (ADEA) and corresponding law in all fifty states, the arbitrary use of age in decisions that impact the employment status of individuals joined the list of prohibited discriminatory behavior. However, Congress recognized that certain occupations are of such importance to public safety as to warrant a reasonable mandatory retirement age. The ADEA provides a safehaven to employers and mandates retirement of pilots and foreign service officers at age sixty five, and air trafiic controllers, federal law enforcement and firefighters at age fifty-six. However, there is no plan in place for Congress to apply a mandatory retirement age to physicians. ${ }^{[39]}$

The parallelism between the Civil Rights Act and the ADEA provides a prism to how age-triggered requirements of latecareer physicians could be viewed through the ADEA. ${ }^{[40]}$ There would not be any doubt that a hospital administration, in its role as employer, violated ADEA if it required hospital cafeteria workers of one faith to take a special skills test; required emergency registration personnel of one gender to take a urine toxicology test; or audited performance metrics of nurses of one race. ${ }^{[41]}$ Singling out physicians of a certain age on the assumption that older physicians are more prone to cognitive impairment constitutes the kind of discriminatory stereotyping prohibited by ADEA. ${ }^{[40]}$

Another way to evaluate age-based competency in the employment context is through disability discrimination. ${ }^{[39]}$ The Federal Rehabilitation Act of 1973 and the Americans with Disabilities Act, and similar state disability discrimination laws prevent employers from requiring medical examination of existing employees without cause. ${ }^{[42]}$ While employers may be permitted under the ADA to require medical examination related to the essential functions of prospective employees if all such prospective employees are subject to such evaluation, employers are restricted in what they may ask or require of employees once they begin work. ${ }^{[43]}$ One interpretation of the ADA could be that an employer might be able to inquire into and examine large groups of employees by claiming the need to ensure that each person within that group could still perform the essential functions of the job. ${ }^{[40]}$ In this way, hospital administrators could define such a group to include all physicians of a certain age and require each physician to undergo cognitive testing while not offending the ADA. However, the Equal Employment Opportunity Commission (EEOC) charged with administrating

Published by Sciedu Press and enforcing civil rights laws against workplace discrimination may take another view. ${ }^{[40]}$ Enforcement Guidance from the EEOC takes the position that an employer must have a reasonable belief on evidence that a particular individual is suffering from a medical condition that impairs job performance or poses a "direct threat". ${ }^{[4]}$ As a result, disability-related inquiries or medical examinations of employees are not to be used to determine whether an employee has a disability where there is no reason to suspect one.

Although age is not a disability under the ADA, the perception that a disability exists because of age can trigger ADA protections. Once age-based competency testing implicates a physical or mental impairment of an employee or casts the specter of doubt amongst colleagues that an employee can perform his job, the employer becomes subject to the ADA's evidentiary requirements. Ironically, unfounded concerns that an employee is in need of cognitive testing can be just as disabling as an actual impairment and can trigger ADA protection, even if the individual in fact has no disability.

\section{OTHER PROBLEMS}

Physicians are not immunized from the disorders they diagnose and treat. Any serious discussion of protecting patients from cognitively impaired physicians must include physicians impaired from causes other than age. However, data on substance use disorders and other psychiatric illnesses among physicians are not well publicized. In large part, this is due to methodological constraints which include the stigma of admitting to symptoms of mental illness or substance abuse and the fear that divulging any impairment might lead to adverse professional consequences. ${ }^{[45]}$ In fact, studies conducted among convenience samples of physicians suggest that rates of substance use disorders among physicians are between $6 \%$ and $15 \%$, no different than that found in the general population. ${ }^{[46]}$ While depression among physicians has also been reported to be similar to age-matched peers $(12 \%$ to $13 \%),{ }^{[47]}$ suicide rates in physicians were found to be significantly higher than those in the general population. ${ }^{[48]}$

Another problem is how to best assess physicians for impaired cognition. Although intelligence derived from higher education has been cited as a confounding factor in the screening of cognitive impairment, how it affects screening remains a subject of debate. One view is that higher education offers protection against the development of dementia, although it is unclear whether it offers the same protection in the conversion from mild cognitive impairment to dementia. ${ }^{[49]}$ A less optimistic view is that strong cognitive reserves derived from higher premorbid intelligence, as well as completion of medical school training, knowledge of positive health maintenance behaviors, and engagement 
in complex medical decision-making merely masks signs of early cognitive decline even when such decline actually exists. ${ }^{[19]}$

In any event, standard cognitive screening tools were not designed to test subjects who possess several years of postgraduate education. Many of the screens for cognitive impairment such as the Mini-Cog, Mini-Mental State Examination (MMSE) and Clock-Drawing Test, while useful in detecting cognitive impairment in the general population, have yet to been validated in physician populations. ${ }^{[50]}$ For instance, a recent study found a cutoff point higher than the traditional MMSE score was required to obtain an acceptable specificity and sensitivity in $90 \%$ of individuals with 16 or more years of education before cognitive impairment could be detected. ${ }^{[51]}$ As it stands, whether intelligence staves off the effects of age-induced cognitive decline or merely masks its detection for any given individual remains unknown.

\section{THE RISE OF AGE-TRIGGERED COGNI- TIVE SCREENING BY HEALTH CARE INSTI- TUTIONS}

Irrespective of the legal implications and limitations of agebased screening of late-career physicians, age-based screening protocols are implemented with increasing frequency by hospital administrators. ${ }^{[52]}$ Estimates place the penetrance of age-triggered cognitive testing within US health systems at about $10 \%{ }^{[53]}$ In light of the growing proportion of latecareer physicians practicing in US hospitals, the increasing call for accountability among healthcare professionals and the need to decrease medical errors, it can be anticipated that this number will increase in coming years.

How can a hospital's age-based mandate for competency screening of its physicians comport with ADA and ADEA prohibitions against discrimination in the workplace? The most obvious answer is both of these laws protect people who fall into the category of "employee". However, physicians may interact with a hospital through practice structures such as solo or partnership practice, professional corporations, or incorporated medical groups which afford them with enumerated hospital privileges without that status of employee. ${ }^{[54]}$ Because of these practice models, questions will arise as to whether ADA or ADEA protections are triggered by a hospital's late-career screening policy. At least one federal circuit court held an orthopedic surgeon's medical "staff privileges" were protected from disability discrimination under Title III of the ADA even without the existence of a formal employee status. ${ }^{[55]}$ Other courts could follow the Menkowitz Court's lead when they deliberate the discrimination issues of non-employee physicians.
The ultimate responsibility of licensing and disciplining physicians and generally assuring the competency of their physician licensees rests with state medical licensing boards. ${ }^{[56]}$ Although the issue of late-career physician competency falls squarely within their purview, age-based competency screening is an emerging topic for these boards. Despite their pre-exiting infrastructure enabling the review of questions of professional competency and to respond by way of practice restrictions, mandated supplementary educations and oversight requirements, it is foreseeable that these boards would support the notion that the first level of competency assessment rests within the local institutions where late-career physicians practice. ${ }^{[39]}$

In 2015, the American Medical Association, Council on Medical Education released a report on "Competency and the Aging Physician" which cites the failure of self-referral and peer recognition and reporting of impaired colleagues and calls for the development of formal guidelines on the timing and content of testing late-career physicians. ${ }^{[57]}$ Similarly, the Joint Commission's standard MS.11.01.01 places the onus of monitoring health matters of licensed physicians on medical administrators and distinguishes this stewardship from disciplinary actions. Although the language in MS.11.01.01 focuses on self-referral and peer recognition, the Joint Commission places the ultimate responsibility of impaired physicians on the medical staff. ${ }^{[58]}$ It stands to reason that the policy statements of these institutions would be construed to mean that the fate of late-career physicians rests with medical administrators of individual hospitals.

\section{OTHER ISSUES}

The difficulties hospital administrators face with assessing late-career physicians do not end with policy implementation. Of paramount importance is what to do when testing uncovers cognitive impairment. If cognitive testing reveals a physician's impairment places patients at immediate risk, eliminating his clinical exposure and possible license forfeiture may be in order. Alternatively, if the condition is potentially reversible, or the deficit potentially remediable, physicians may be referred to special programs for further competency and practice assessments and remediation. ${ }^{[59]}$ Unique confidentiality issues accompany age-triggered cognitive screening. For instance, if the screening is conducted in the employment context, the Health Insurance Portability and Accountability Act (HIPAA) will not afford protection to medical information obtained during the test because HIPAA does not protect employment records. ${ }^{[39]}$

How other countries ensure the competency of their medical practitioners only serves to confirm the lack of consensus on essentially every aspect of how and when to conduct these 
assessments. Canada, New Zealand, Australia and the United Kingdom have adopted programs ranging from blanket monitoring to targeting tiers of physician groups that deserve special attention. ${ }^{[60]}$ For instance the Medical College of New Zealand mandates review of all its physicians who register in general scope of practice. ${ }^{[61]}$ In addition to blanket monitoring, Canada recognizes tiers of at-risk physician groups one of which includes late-career physicians and those who work in relative professional isolation. Each provincial College of Physicians and Surgeons regulates how to assess each physician tier. ${ }^{[62]}$ An international comparison of assessment tools, referral mechanisms, legislative support and other issues serves to raise more questions than provide answers to the question of how best to assess the provision of care provided by medical practitioners and especially late-career physicians.

\section{ESTABLISHing THE MOUNTAINSIDE POL- ICY}

The Chief Medical Officer, Dr. Valerie Allusson, summarized her experience when she instituted a late-career physician policy at Mountainside Medical Center. Reviewing research on late-career physicians, familiarizing ourselves with similar policies from other institutions and educating ourselves on relevant law were the first steps. Crafting a draft policy was another initial step, followed by formation of a Wellness Committee which led the protocol through its implementation which included providing the medical staff with research supporting the policy, the rationale behind the testing and framework for the testing process. This step prepared the medical staff for several notice and comment meetings to be held with the medical community.

I personally reached out to several practitioners who would be imminently affected by the policy during its development to invite their individual comments and concerns. Annually, the policy principles will be reiterated to include new members of the medical staff. After the policy is solidified and promulgated, the Wellness Committee begins by soliciting feedback from the medical staff. This includes discussion of which screening tools to be used and agreement on who will be administering the assessment. Finally, action plans can be discussed in the event cognitive screening reveals the possibility that a late-career physician's medical practice could be compromised. Implementing our policy involved input from several consultants including: "the Medical Executive Committee, Office of the General Council, Credentialing Committee, Psychiatry, Geriatric Medicine, Office of the Chief Medical Officer and various departmental Chairpersons and Section Chiefs".

\section{Conclusions}

With two-fifths of the US physician workforce over the age of sixty-five, hospital administrators are increasingly faced with the problem of detecting cognitive decline among their medical staff ranks. The actions they take must balance patient safety against the risk of disparate and possibly illegal screening. After a review of the literature Mountside Medical Center adopted age-triggered evaluation of late-career physicians. We found instituting this policy to be a monumental task complicated by legal issues, limitations in testing modalities, and the problem of what to do when cognitive decline is detected.

The process of instituting this policy reminded us of the importance of the physician's age in medicine. While other disciplines adopted mandatory age-triggered retirement, medicine has not. We think the medical profession does not lag in this regard but leads. Age should not represent an angle of repose for late-career practitioners. Age is a shield against the folly of inexperience whose cost can only be paid through time. But age is also a dagger that exploits the human frailty of its pupils and cruelly takes back the knowledge it previously provided. As shield and dagger, age is both ally and foe to medical providers. Policies to address late-career physicians must recognize this dichotomy.

\section{ACKNOWLEDGEMENTS}

The authors give special thanks to the editing guidance of Mrs. Paula Schonewald.

\section{CONFLicts OF InTEREST Disclosure}

The authors declare they have no conflicts of interest.

\section{REFERENCES}

[1] AMA Physician Masterfile Data from 1975-2017, Chicago, IL: American Medical Association.

[2] American Medical Association. Competency and the Aging Physician. Report 5 of the Council on Medical Education (A-15). Chicago, IL: AMA; 2015.

[3] Association of American Medical Colleges. Active Physician by Age

Published by Sciedu Press and Specialty. 2015. Available from: https://www.aamc.org/d ata/workforce/reports/458490/1-2-chart.html

[4] Eve KW. The aging physicians: changes in cognitive processing and their impact on medical practice. Acad Med. 2002; 77(10 suppl): S1-S6. PMid: 12377689. https://doi.org/10.1097/00001888 -200210001-00002

[5] Eve KW. Stemming the tide: cognitive aging theories and their 
implications for continuing education in the health professions. $\mathbf{J}$ Contin Educ Health Prof. 2003; 23(3): 133-140. PMid: 14528783. https://doi.org/10.1002/chp.1340230303

[6] Jackson GR, Owsley C. Visual dysfunction, neurodegenerative diseases, and aging. Neurol Clin. 2003; 21(3): 709-728. https: //doi.org/10.1016/S0733-8619(02)00107-X

[7] Jackson GR, Owsley C, Cordle EP, et al. Aging and scotopic sensitivity. Vision Res. 1998; 38(22): 3655-3662. https ://doi.org/10 .1016/S0042-6989(98)00044-3

[8] Waljee JF, Greenfield LJ, Dimick JB, et al. Surgeon age and operative mortality in the United States. Ann Surg. 2006; 244(3): 353362. PMid: 16926561. https://doi.org/10.1097/01.sla.000 $0234803.11991 .6 \mathrm{~d}$

[9] Powel DH, Whitla DK. Profiles in Cognitive Aging. Cambridge MA: Harvard University Press; 1994.

[10] Korinek LL, Thompson LI, McRae C, et al. Do physicians referred for competency evaluations have underlying cognitive problems? Acad Med. 2009; 84: 1015-1021. PMid: 19638765. https : //doi.org/10.1097/ACM.0b013e3181ad00a2

[11] Pesiah C, Adler RG, Williams BW. Australian pathways and solutions for dealing with older impaired doctors: a prevention model. Intern Med. J. 2007; 37: 826-831. PMid: 18028084. https://doi. $\mathrm{org} / 10.1111 / \mathrm{j} .1445-5994.2007 .01504 . \mathrm{x}$

[12] Norton PG, Foulkner D. A longitudinal study of performance of physician's office practices: data from the Peer Assessment Program in Ontario, Canada. Jt Commiss J Qual Improv. 1999; 25: 252-258. https://doi.org/10.1016/S1070-3241(16) 30442-4

[13] Morrison J, Wickerman MS. Physicians disciplined by a state medical board. JAMA. 1998; 279: 1889-1894. PMid: 9634260. https : //doi.org/10.1001/jama.279.23.1889

[14] Waljee, Jennifer F, Greenfield, et al. Surgeon age and operative mortality in the United States. Annals of Surgery. 2006; 244: 353-362.

[15] Day SC, Norcini JJ, Webster GD, et al. The effect of changes in medical knowledge on examination performance at the time of recertification. Res Med Educ. 1988; 27: 138-144.

[16] Cohen R, Swankin D, Citizen Advocacy Center, Hospital Reporting to State Regulators and to the National Practitioner Data Bank. March 1997; 21.

[17] American Medical Association. Competency and the Aging Physician. Report 5 of the Council on Medical Education (A-15). Chicago, IL: AMA; 2015.

[18] Citizen Advocacy Center, in collaboration with the Administrators in Medicine. A Model Act to Improve Reporting of Adverse Actions by Health Care Organizations to State Health Professional and Occupational Licensing Authorities. March 1999.

[19] LoboPrabbu SM, Molinari VA, Hamilton JD, et al. The aging physician with cognitive impairment: Approaches to oversight prevention, and remediation. Am J Geriatr Psychiatry. 2009; 17: 445454. PMid: 19461256. https://doi.org/10.1097/JGP. 0b013e $31819 \mathrm{e} 2 \mathrm{~d} 7 \mathrm{e}$

[20] Campbell EG, Regan S, Gruen RL, et al. Professionalism in medicine: results of a national survey of physicians. Ann Intern Med. 2007; 147: 795-802. PMid: 18056665 . https://doi.org/10.7326/00 03-4819-147-11-200712040-00012

[21] Clay SW, Conaster RR. Characteristics of Physicians Disciplined by the State Medical Board of Ohio. 103 J AM Osteopathic Ass'n. 2003 81: 64.

[22] During SJ, Artino AR, Holmboe E, et al. Aging and cognitive performance: challenges and implications for physicians practicing in the 21 st century. J Contin Edu Health Prof. 2010 Summer; 30(3): 153-60. PMid: 20872769. https://doi.org/10.1002/chp. 20075
[23] Mountier CY, Bazzo DEJ, Norcross WA. Approaching the Issue of the Aging Physician Population (Data from the Coalition for Physician Enhancement Conference). Journal of Medical Regulation. 2013; 99(1): 10-18. https://doi.org/10.30770/2572-1852-99.1. 10

[24] Jackson GR, Owsley C. Visual dysfunction, neurodegenerative diseases and aging. Neuro Clin. 2003; 21: 709-728. https://doi.or $\mathrm{g} / 10.1016 / \mathrm{S} 0733-8619(02) 00107-\mathrm{X}$

[25] Rhee So. Factors determining the quality of physician performance in patient care. Med Care. 1976; 14: 733-750. PMid: 972566. https://doi.org/10.1097/00005650-197609000-00002

[26] Choudry NK, Fletcher RH, Soumerai SB. Systematic review: The relationship between clinical experience and quality of healthcare. Ann Intern Med. 2005; 142: 260-273. PMid: 15710959. https: //doi.org/10.7326/0003-4819-142-4-200502150-00008

[27] Southern WN, Billin EY, Arnsten JH. Longer lengths of stay and higher risk or mortality among inpatients of physicians with more years in practice. Am J Med. 2011; 124: 868-874. PMid: 21745651. https://doi.org/10.1016/j.amjmed.2011.04.011

[28] McAuley RG, Paul WM, Morrison GH, et al. Five-year results of peer assessment program of the College of Physicians and Surgeons of Ontario. CMAJ. 1990; 143: 1193-1199.

[29] Ashworth M, Schofield P, Seed P, et al. Identifying poorly performing general practices in England: A longitudinal study using data from the quality and outcomes framework. J Health Serv Res Policy. 2011; 16: 21-27. PMid: 21186318. https://doi.org/10.1258/jhsrp. 2010.010006

[30] Kohatsu ND, Gould D, Ross LK, et al. Characteristics associated with physician discipline. Arch Int Med. 2004; 164: 653-658. PMid: 15037494. https://doi.org/10.1001/archinte.164.6.653

[31] Grace ES, Wenghofer EF, Korinek EJ. Predictors of physician performance on competence assessment findings from CPEP, the Center for Personalized Education for Physicians. Acad Med. 1994; 69(10 suppl): S16-S18.

[32] Goulet F, Jacques A, Gagnon R, et al. Performance assessment: Family physicians in Montreal meet the mark! Can Fam Physician. 2002; 3: 269-277.

[33] Kupfer JM. The graying of US physicians: Implications for quality and the future supply of physicians. 2016; 315: 341-342. PMid: 26720141. https://doi.org/10.1001/jama.2015.18248

[34] Lee JH. Results from the cognitive changes and retirement among senior surgeons self-report stud. J AM C. Surg. 2009; 688: 669-670.

[35] Tsugawa Y, Newhouse JP, Zaslavsky AM, et al. Physician age and outcomes in elderly patients in hospital in the US: observational study. BMJ. 2017; 357. PMid: 28512089. https://doi.org/10 $.1136 / \mathrm{bmj} \cdot \mathrm{j} 1797$

[36] Taragin MI, Wilczek AP, Karns ME, et al. Physician demographics and the risk of medical malpractice. American Journal of Medicine. 1992; 93(5): 537-42. https://doi.org/10.1016/00 02-9343 (92) 90582-V

[37] Fathy CA, Pichert JW, Domenico H, et al. Association Between Ophthalmologist Age and Unsolicited Patient Complaints. JAMA Ophthalmology. 2017. PMid: 29192303. https ://doi .org/10.1 001/jamaophthalmol.2017.5154

[38] Beyondblue, National mental health survey of doctors and medical students. 2013. Available from: https://www . betondblue.org .au/docs/default-source/research-project-files/bl1 132-report--nmhdmss-full-reportweb

[39] Chase-Lubitz J. Legal issues and the aging physician. R I Med J. 2017; 23-25.

[40] Moore IN. Screening Older Physicians for Cognitive Impairment: Justifiable or Discriminatory? (January 1, 2017). 28 Health Matrix: 
Law-Medicine J. March 2018. Available from: https://ssrn.com /abstract $=2954834$

[41] Kataria N. A retrospective study of cognitive function in doctors and dentists with suspected performance problems: an unsuspected but significant concern. 5 Royal Soc'y Med. 2016; 1: 3.

[42] 42 U.S.C. § 12101 et. Seq. US Dep't of Justice Civil Rights Div., Employment (Title 1) ADA. 2017. Available from: http: /www . ada .gov/adatitleI.htm. (last visited April 12, 2019).

[43] 42. U.S.C. § 12112 (d) (2)-(3). 2017.

[44] EEOC Enforcement Guidance NO. 915.002, Disability-related inquiries and medical examinations of employees under the Americans with Disability Act (ADA). 2000. Available from: http: //eeoc.gov/policy/docs/guidance-inquiries.html

[45] Marshall EJ. Doctors' health and fitness to practise: treating addicted doctors. Occup Med (Lond). 2008; 58: 334-40. PMid: 18676427. https://doi.org/10.1093/occmed/kqn081

[46] Baldisseri MR. Impaired healthcare professional. Crit Care Med. 2007; 35: S106-16. PMid: 17242598. https://doi.org/10.109 7/01. CCM.0000252918.87746.96

[47] Dyrbye LN, Thomas MR, Shanafelt TD. Systematic review of depression, anxiety, and other indicators of psychological distress among U.S. and Canadian medical students. Acad Med. 2006; 81: 35473. PMid: 16565188. https://doi.org/10.1097/00001888-2 00604000-00009

[48] Lindeman S, Laara E, Hakko H, et al. A systematic review on genderspecific suicide mortality in medical doctors. Br J Psychiatry. 1996; 168: 274-9. PMid: 8833679. https://doi.org/10.1192/bjp. 168.3 .274

[49] Bruscoli M, Lovestone S. Is MCI really just early dementia? A systematic review of conversion studies. Int Psycholgeriatr. 2004; 16: 129-140. https://doi .org/10.1017/S1041610204000092

[50] Boustani M, Peterson B, Halson L, et al. Screening for dementia in primary care: a summary of the evidence for the U.S. Preventive Services Task Force. Ann Intern Med. 2003; 138: 927-937. PMid: 12779304. https://doi .org/10.7326/0003-4819-138-11-2 00306030-00015
[51] O'Bryant SE, Humphrys JD, Smith GE, et al. Detecting dementia with the mini-mental state examination in highly educated individuals. Arch Neurol. 2008; 65: 963-967. PMid: 18625866. https://doi.org/10.1001/archneur.65.7.963

[52] Washington Post. Accessed 4-25-19. Available from: Www . washingtonpost . com/national/health-science /as-doctors-grow-old-hospitals-begin-requiring-the m-to-prove-theyre-still-fit/2012/12/10/42bb4d90-2 d0e-11e2-a99d-5c4203af7b7a_story.html

[53] Medpage Today. Available from: https://www .medpagetoday.c om/publichealthpolicy/generalprofessionalissues/78 554

[54] See New Physician Practice Options: Choosing your practice setting, STAFF CARE. Jan 21, 2016. Available from: https://www.staffcare.com/physician-practice-optio ns-choosing-your-practice-setting/

[55] Menkowitz V. Pottstown Memorial Med. Ctr., 154 F.3d 113, 122 (3d Cir). 1998.

[56] Dent v West Virginia, 129 U.S. 114, 122. 1889.

[57] AMA Report of the Council on Medical Education, Competency and the Aging Physician. November 2015.

[58] The Joint Commission. 2015 Comprehensive Accreditation Manual for Hospitals: The Patient Safety Systems. Chapter MS.09.01.01.

[59] Hawkins RE, Welcher CM, Elliot VS, et al. Ensuring Competent Care by Senior Physicians. J Contin Educ Health Prof. 2016; 36: 226-231. PMid: 27584000. https://doi.org/10.1097/CEH.00 00000000000080

[60] St. George I, Kaigas T, McAvoy P. Assessing the competence of practicing physicians in New Zealand, Canada, and the United Kingdom: progress and problems. Fam Med. 2014; 36: 171-177.

[61] Soonsawat A, Tanaka G, Lammando M, et al. Cognitively Impaired Physicians: How do we detect them? How do we assist them? Am J Geriat Psychiat. 2018; 26: 631-640. PMid: 29523462. https://doi.org/10.1016/j.jagp.2018.01.203

[62] Cambell CM. Revalidation of Canadian physicians. CMAJ. 2009; 180: 539-540. PMid: 19255078. https://doi.org/10.1503/cm aj. 1080127 